Revista Española de Antropología Americana ISSN: 0556-6533

https://doi.org/10.5209/REAA.63694

\title{
Los sacrificios humanos y su relación con la dieta y el canibalismo azteca en el momento de la Conquista
}

\author{
Jesús Ruvalcaba Mercado ${ }^{1}$
}

Recibido: 7 de abril de 2017 / Aceptado: 2 de febrero de 2018

Resumen. Los sacrificios humanos y el canibalismo son temas que atraen el interés de la humanidad a nivel popular y científico. El asunto es problemático, pero académicamente apasionante por su contenido y significado. En este contexto, los objetivos de estas líneas son analizar algunas fuentes y sus contradicciones para dilucidar la función del sacrificio humano más generalizado entre los mexica y su relación con la antropofagia y la dieta de la población común. Para ello, se cotejan las cifras que ofrecen las crónicas y se ponen en la palestra otras posibles explicaciones. Se conmina también al lector a justipreciar esos documentos de manera crítica para así aprovechar su verdadero valor.

Palabras clave: sacrificio humano; antropofagia; sociedad mexica; cronistas españoles; lectura crítica.

\section{[en] Human Sacrifices and their Relationship with Aztec Diet and Cannibalism at the Time of Conquest}

\begin{abstract}
Human sacrifices and cannibalism have attracted the popular and scientific interest of humanity. Their relationship is problematic but academically exciting given its content and meaning. In this context, the aims of these lines are to analyze some sources and their contradictions to elucidate the meaning of Aztec human sacrifice in its most usual form, and its connection with cannibalism, and the diet of common people. To accomplish them, we will compare the numbers that the chronicles offer us, and bring forward other possible explanations. The reader is encouraged to appraise these documents in a critical way in order to take advantage of their true value.
\end{abstract}

Keywords: human sacrifice; cannibalism; Aztec society; Spanish chroniclers; careful reading.

Sumario. 1. Planteamiento. 2. Exordio. 3. Las polémicas. 4. Algo sobre las fuentes. 5. De nuevo con los textos. 6. Contradicciones e inconsistencias de los cronistas. 7. Colofón. 8. Referencias.

Cómo citar: Ruvalcaba Mercado, Jesús. 2018. «Los sacrificios humanos y su relación con la dieta y el canibalismo azteca en el momento de la Conquista». Revista Española de Antropología Americana 48: 121-142.

\section{Planteamiento}

Los sacrificios humanos y el canibalismo, asociados o de por sí, han despertado gran interés entre la humanidad a nivel popular y científico. El asunto plantea problemas

\footnotetext{
1 Centro de Investigaciones y Estudios Superiores en Antropología Social, México. ruvalca@ciesas.edu.mx
} 
académicos y pasiones diversas por su contenido y significado ${ }^{2}$. Con todo y la abundante tinta vertida a su alrededor, siguen las controversias, polémicas y agrios desacuerdos. Aquí nos centraremos sólo en los datos duros y dejaremos de lado mitos, leyendas y cosmogonía, que son también relevantes, pero quedan fuera de nuestro ámbito y alcance. Hecha la indicación, enseguida se analiza lo que trasmiten algunas fuentes sobre el sacrificio humano entre los aztecas y su relación con la dieta mayoritaria. En el medio académico abundan los estudios históricos y actuales sobre los tres temas, muchos cargados de prejuicios, justificaciones o rechazos viscerales que no ayudan a entender su función (ni otros temas) en Mesoamérica. Con la mitad que se hubiera descrito la actividad central y generalizada, la agricultura, entenderíamos mejor esas culturas. Sobre los sacrificios y la antropofagia, la mayoría se concentra en el periodo mexica (azteca) y su capital Tenochtitlan que, en comparación, representa un breve lapso geográfico e histórico, casi accidental, en el devenir de esa antigua y diversa súper área cultural.

La controversia se originó en el siglo XVI, aunque varios autores la ignoran o la pasan por alto; sus discrepancias tienen varias aristas, de las que con visos científicos se recurre a tres parcialmente ciertas ahora muy cuestionadas: la preferencia humana por la carne y la grasa animal, la circunscripción territorial del Valle de México más su degradación durante el siglo XV y la presión demográfica. De allí se derivan postulados sobre el canibalismo azteca que comprenden dos tendencias divergentes en sus motivos y excluyentes en sus conclusiones. Una asume que la guerra y los sacrificios humanos eran actos relacionados con el ejercicio del poder y conforman un complejo con alto significado político y ritual: la guerra para sujetar a otras provincias y hacerlas tributarias (a la vez que para entrenar a los jóvenes en la batalla) y los sacrificios como amenaza para pueblos vecinos y los mismos tenochca si rechazaban el sojuzgamiento. Que en general, los grupos de Mesoamérica -incluidos los aztecas- comían un abanico mucho más amplio de vegetales y animales que el que ahora consumimos (Gibson 1967: 345-350; Ortiz de Montellano 1978: 612; Santley y Rose 1979; Castile 1980: 390; González 2012: 90). Que sólo unos pocos nobles privilegiados probaban carne humana mientras que la gente común comía tanto insectos, gusanos, larvas, aves, espirulina, animales de caza y domésticos como guajolote, perrillo, patos, codornices, ánsares y otras presas silvestres y acuáticas que bien podía cubrir las necesidades de proteína y grasa animal (Parsons 2008: $353,364)$. Según este enfoque, sacrificio y canibalismo no atañen al mismo conjunto (Price 1978: 101).

La otra data del siglo XVI y afirma que las guerras mexica - o mesoamericanasse debían precisamente al apuro por conseguir carne humana para el consumo, como parte de un sistema político, social y ambiental cuyo propósito era capturar prisioneros a fin de traerlos a Tenochtitlan para engordarlos, sacrificarlos (a Huitzilopochtli, Xipe Totec, Toci y a otros dioses) y, finalmente, ser comidos por los nobles o incluso por el pueblo común. Esta propuesta asume que el crecimiento poblacional llegó a los límites que recursos y tecnología disponibles permitían y, por lo tanto, la presión demográfica se hizo insostenible en un medio ambiente agotado. Al no contar con

\footnotetext{
Esta temática resulta ineludible al hablar de la dieta prehispánica por lo que implica para la historia y para el presente. Aquí retomé un par de ideas expresadas en otro escrito, con el que aparte de ello, éste guarda poca relación (Ruvalcaba 1999). Agradezco al lector anónimo designado por la REAA sus observaciones para precisar, reflexionar y mejorar el resultado.
} 
grandes animales domésticos, los mesoamericanos recurrieron a fuentes alternas de proteínas, insectos y otras formas repudiadas (por los europeos, y no por todos), lo mismo que al canibalismo para obtener cantidades significativas de carne y grasa animal. Marvin Harris (1989: 288, 305) refuta que dichas fuentes pudieran subsanar los requerimientos por el tiempo necesario para cazar los bichos y la poca eficiencia del pavo y perro para producir carne, «a pesar de la impresión de abundancia (...) la ración diaria de carne, pescado y aves no superaba casi con toda seguridad unos pocos gramos» por cabeza.

Una tercera tendencia comprende enfoques y propuestas de índole diversa que, sin negar la antropofagia, primero, separan la guerra del canibalismo y, segundo, no relacionan a una ni al otro con la ecología, la disponibilidad de proteína animal o la ubicación (circunscripción) del valle del Anahuac, sino más bien con cuestiones simbólicas y rituales propias de la cosmogonía indígena (Olivier y López Luján 2010: 36). Lo que se puede asegurar es que sacrificios y consumo de carne humana se esgrimieron para apoyar y justificar la conquista, la guerra, el saqueo y la expoliación de los cuantiosos recursos que América guardaba en su seno y la explotación de la mano de obra de sus legítimos dueños.

Aunque un año antes ya Carlos V había mandado llevar animales para que su carne «sustituyera» la de los humanos, el primer occidental que lanzó la interpretación integral que luego se transformó y perdura como premisa sobre el sacrificio humano en las tierras recién conquistadas fue Rodrigo de Albornoz, su contador, quien le comunicó por carta (diciembre, 1525) que los indios de México la comían debido a tradiciones heredadas, por «la penuria» de no tener cerdos, reses, cabras y ovejas y por ser su gusto o su costumbre. Según el mismo, en cuatro años los aztecas perdieron la predilección y afición por comerse al prójimo, cuya carne les era «más dulce» que cualesquiera otras. Así que el punto de vista sobre la gran cantidad de sacrificados para luego surtir la alacena, sostenido por Michael Harner y otros, no es original, pues, aunque no se lo reconocen, el contador lo expresó siglos atrás, incluso de manera más elocuente. Dice:

«Como V. S. M. es informado, la gente destas partes comen carne humana, así por lo haber acostumbrado de sus pasados, como por la penuria que (...) ha habido entre ellos de no tener ganados; y porque también acostumbrados á la carne humana, les es más dulce que la de aves é caza que tienen é crían $^{3}$; y después que la tierra está en el dominio de V. M., con la conversación y trato de los cristianos comen aves de Castilla y puercos y carnero y vaca, y las otras carnes que ven comer á los cristianos, y beben vino de España con mejor voluntad que el pulque» (Albornoz 1980 [1525]: 488).

Los frailes en general añadieron otra explicación basada en los prejuicios de la época: que los sacrificios y el canibalismo (la religión en general) eran uno de tantos ardides del demonio, por cuyo castigo incluso se produjo la catástrofe demográfica.

\section{Exordio}

Para ubicar el sacrificio humano y la antropofagia en una dimensión más apropiada hay que señalar varios aspectos. En primer lugar, entre los mexica, la ofrenda de

\footnotetext{
3 La de los españoles no les apetecía porque la «han probado y son duros y amarga la carne dellos», añade don Rodrigo.
} 
seres humanos no era indiscriminada; la prioridad era inmolar cautivos y esclavos (y no a todos, puesto que a algunos se les esclavizaba como sirvientes). De los que se ofrendaban, su muerte se debía a dos acciones básicas: aquellos -hombres principalmente- que se cautivaban en la guerra, llamados «la dulce comida de los dioses» (Durán 1984, I: 181; cap. XX, § 18), que eran los que adquirían mayor valor simbólico y comercial ${ }^{4}$, a mayor distancia, más valor; y los esclavos -hombres, mujeres, niños y niñas incluidos-, originarios de la propia comunidad o de alguna ajena, que por algún delito $-\mathrm{o}$, en el caso de los menores, por una crisis familiar o porque sus padres los consideraban incorregibles- se hacían acreedores, primero a ser esclavizados y, luego, no todos, a la pena de muerte. Según las fuentes, los guerreros predilectos eran los capturados en Tlaxcala, Huejotzingo, Metztitlán, Cholula, Atlixco, Tliliuhquitepec y Tecoac (Durán 1984, II: 233; Cap. XXVIII, § 46-49; Alvarado Tezozomoc 1980: 101; Benavente 1914: 44, cap VII), todas en el rango de unos 100 kilómetros de distancia desde Tenochtitlan, y en las fiestas de Tititl exclusivamente los de Pánuco, por su fama de guerreros y traerlos desde tan lejos, acota Motolinía 5 . Junto a los guerreros apresados, los esclavos sacrificados obtenidos por tributo igual se asocian a la antropofagia. Es decir, se admite que los pueblos sometidos cedían a sus congéneres para que fueran engordados, sacrificados y luego comidos.

Motolinía y, con mayor precisión, Durán dejan claro que sacrificio humano y esclavitud eran castigos reglamentados contra los capturados en la guerra y los que de forma consistente quebrantaban la ley dentro de la comunidad. Fray Diego Durán (1984, I: 182-186; cap. XX, § 23-40) establece que el castigo de la esclavitud que podía desembocar en el sacrificio se aplicaba a quienes reincidían por robo, los «que cometían delitos atroces», quienes apostaban y perdían su libertad, los hijos cuyos padres los consideraban como disolutos, desvergonzados, desobedientes o incorregibles; por no pagar las deudas adquiridas, los criados que rompían tabúes; los homicidas a quienes los deudos del muerto optaban porque fuera ejecutado o que, vivo, les trabajara o les sirviera como otros hacían (Alvarado Tezozomoc 1980: 103) o hacen ahora los yaquis; en tiempo de hambrunas si los cónyuges decidían que uno se vendiera con la esperanza de rescatarlo al mejorar la situación y «por otros muchos delitos». Al mismo tiempo, la ley les ofrecía la posibilidad de tornarse libres cuando los que empeñaban su persona preferían la prisión o resarcían el daño o la deuda causa de su desgracia. Igualmente, esclavos y cautivos podían reconquistar su libertad al escapar de su dueño y salir del mercado sin ser atrapados. Excepto ellos dos, el cautivo y su dueño, nadie podía interferir, ya que quien lo hacía ocupaba el lugar del esclavo mientras éste quedaba libre.

Como se puede deducir, inmolar a los cautivados en la guerra y los condenados por delitos era una ejecución a la vez que sacrificio, excepto, quizá, el de los ofrendados por meras cuestiones religiosas (González 2012: 202-203). O sea, comprendían el castigo, para los renuentes a tributar y los delincuentes contumaces, y la comunión de las elites con sus dioses, para asegurar el equilibrio y la marcha del universo, «alimentar al sol», etc. Durán afirma que los esclavos no iban directos al matadero

\footnotetext{
4 El calificativo de la carne humana como «la más dulce» y preferida sobre cualesquiera otras, se usó en Europa desde años atrás, junto a imágenes inverosímiles y ficticias para denostar a los pueblos marginales (Grafton en Carrasco 1995: 430-431).

5 Aseveración que contradice parte de los argumentos de peso de Graulich (2016: 209; 228): «Al hablar de los guerreros se observó ya la tendencia a sacrificar de preferencia a gente cercana, más emparentada y por lo tanto mejor» porque la víctima sustituía al sacrificante.
} 
sino cuando reincidían en el juzgado crimen y, aun así, sólo con la aprobación de los jueces. Por su lado, Albornoz (1980: 493) apunta que con «mucha ligereza», los aztecas «por cosas muy fáciles y de burla se hacen unos á otros esclavos».

Si bien el tema ha captado la constante curiosidad de la humanidad, el artículo de Harner sobre los aztecas (1977), catapultado por la publicidad mundial (Graulich 1991: 130; 2016: 47-48), aunque reduccionista, incentivó la discusión global en una amplia gama de estudios sociales en diferentes lugares del mundo, dado el reto que lanzó acerca de que guerras y sacrificios mexica tenían como fin un «canibalismo en gran escala» como natural consecuencia del deterioro del medio y la carencia de grandes animales. El resultado fue una voluminosa bibliografía aparecida desde cuando escribiera su artículo ${ }^{6}$. Aparte del ajado argumento acerca de la ausencia de mamíferos que sustituyeran la carne humana, destacó la circunscripción territorial del valle (1977: 118-119; Harris 1989: 153), agotado por su continuada ocupación desde antes de Cristo, las actividades específicas y el crecimiento demográfico durante el siglo XV (Cook 1946). Como apoyo indiscutible, se presentan las cifras de sacrificios que nos trasmiten los cronistas y los propios indígenas.

\section{Las polémicas}

Un matiz de esta posición fue expresado por Marvin Harris. Luego de modificar sus argumentos sobre la guerra y el complejo sacrificial de los aztecas como suministro de proteína animal (1987: 153, 168), asegura que el canibalismo militar mexica, como pasa en las sociedades preestatales, era un «subproducto habitual» y no su objetivo principal. Para ellos los prisioneros tenían más o menos la misma utilidad residual, pero mejor los preferían muertos por su carne que vivos como sirvientes esclavos. Así que los gobernantes mexica mantuvieron el canibalismo a pesar de sus consecuencias económicas para el Estado tributario (Harris 1989: 306-307).

A las motivaciones ideológicas, históricas y actuales, se añaden la sed de sangre de los aztecas, la tradición de sus dioses (es decir, «sus costumbres» según Albornoz y Graulich $\left.{ }^{7} 2016: 39\right)$ más la habilidad del diablo para mantenerlos engañados (Motolinía, Sahagún, Durán). Contra estas «bárbaras costumbres» los españoles se invistieron con la «sagrada misión» de conquistar, convertir y, por lo tanto, destruir esa religión como de manera sistemática e insistente lo estipulan soldados, frailes, funcionarios y encomenderos. Este proselitismo o evangelización autoimpuesta es sólo un eufemismo con el que se oculta la destrucción de la sociedad y las culturas mesoamericanas, puesto que la religión jugó un papel central en todo tiempo y lugar en su desarrollo. Todo ello, según Sophie Coe (2004: 161):

«... da luz al viejo cliché según el cual los aztecas eran unos militaristas sedientos de sangre, dejándolo como una sobresimplificación ridícula, producto de la autojustificación de los europeos que ha sobrevivido a causa de ese rasgo sombrío que nubla nuestro pensamiento».

\footnotetext{
${ }^{6}$ La propuesta de Harner se ha rebatido desde varios enfoques (Price 1978: 107; Carrasco 1995: 433; Coe 2004: 147-149; Calavia 2009) sin que dejen de repetirse sus desaciertos académicos o de usarse para apoyar comparaciones absurdas, como entre los aztecas y los nazis, por ejemplo.

7 Sin citar al primero, este autor ubica las razones profundas, la «respuesta más realista» del sacrificio masivo, en la «costumbre, porque desde la infancia lo habían visto y aprendido, porque así se había hecho en Mesoamérica por generaciones (...), siglos o (...) milenios» (2016: 39).
} 
Así, bajo el yugo español se buscaba mantener alejados a los indios de sus «prácticas religiosas abominables», pero no terminar con la injusticia tributaria, la inequitativa distribución de los recursos, eliminar la estratificación, etc.

En resumen, a pesar de contar con análisis, datos e interpretaciones más detallados sobre el sacrificio humano y la antropofagia, los desacuerdos todavía se basan en: 1) la supuesta insuficiencia de proteínas en la dieta cotidiana y el desconocimiento parcial de la enorme variedad de alimentos que componían la dieta de la gente común; 2) la distorsión de las cifras en las crónicas y su textual aceptación; y 3) la falta de fuentes imparciales, verificables, así como la lectura acrítica de las que existen (Ortiz de Montellano 1978: 615-616). Sin poder agotar todas las caras del problema, enseguida se referirán el punto 2, la imposibilidad de las cifras argüidas, y el 3, la problemática de las fuentes ${ }^{8}$.

En Mesoamérica, religión, política y economía formaban un todo para gobernar y manipular a los trabajadores. Por ende, es imposible aislarlas y ver las ejecuciones sólo como sacrificios expiatorios, así todas fueran acompañadas de rituales tan pulidos. Las afirmaciones en contra repiten errores históricos o contemporáneos, debidos al etnocentrismo y a la consulta parcial de las fuentes. Al leerlas sin criterio «la única perdedora fue [es] la verdad» (Coe 2004: 148-149). Sin ser nuevo del todo (Ingham 1984: 379), propongo que en el Triple Señorío no hubo canibalismo para obtener comida $^{9}$, sino que los sacrificios respondían a una política de Estado.

La asociación entre el sacrificio humano y el canibalismo entre los aztecas, que autores históricos y modernos consideran indefectiblemente enlazados, al asumir que esclavos y cautivos, sin excepción, estaban destinados a las ollas y barrigas de la nobleza o incluso de los macehuales, resulta insostenible. Las crónicas especifican que al pueblo común en Tenochtitlan y otras partes le estaba prohibido comer carne humana o, incluso, comer carne en general, vestir de algodón, calzar zapatos, usar adornos como joyas de oro o chalchihuites, vestir mantas adornadas, cazar en los cotos reservados a la nobleza, etcétera. Fray Diego Durán afirma sobre este punto que «la gente común jamás la comía [la carne humana], sino allá la gente ilustre y muy principal» (1984, I: 108; cap. X, § 14).

Existió sin duda el asesinato ritual o ajusticiamiento estatal en diferentes áreas y épocas, y ya al momento de la conquista, no sólo por los mexica, sino también por huejotzincas, tlaxcaltecas, meztitlecos, cholultecas y otros pueblos. Lo que pareció escandaloso a los recién llegados fue la parafernalia sangrienta de la ejecución. La fuente en que se basaron Durán, Tezozomoc y Acosta, el llamado Códice Ramírez, resalta que los sacrificios eran una exhibición previa a la guerra o al arrasamiento, para persuadir a amigos y enemigos a que tributaran al Triple Señorío. Como asunto bajo el control exclusivo y absoluto del Estado y los sacerdotes (González 2010: 402; 2012: 224, 242), su fin era amedrentar, amenazar y controlar a extraños y a su propia población; por medio del terror, añade esta autora (p. 243). Es obvio que Tenochtitlan y las ciudades aliadas en el valle requerían de grandes cantidades de comida importada además de la que producían; así lo señalan los registros pedidos por el primer virrey de México. Y vale recordar que el tributo incluía desde pulgas y piojos hasta comida, oro, mantas y piedras pre-

\footnotetext{
8 Para el punto 1, la composición de la dieta, Ruvalcaba (2017). Ver nota 19.

9 Un punto de vista opuesto en González (2012: 297), quien admite el sacrificio «gastronómico»; por la «afición a la carne humana», limitado a los privilegiados.
} 
ciosas (Durán 1984, II: 367; cap. XLVII § 21). Pero esto está lejos de confirmar, como escribe Fernández-Armesto (2004: 150-151), que los alimentos en el Valle sólo se producían en las chinampas.

Entramos así en otro ámbito de la disputa: las cifras tan divergentes y su grado de veracidad. Aun si se acepta que la esclavitud y pena de muerte no conducían al canibalismo, falta esclarecer la magnitud y el sentido del sacrificio de los guerreros cautivos, los esclavos y de la antropofagia en la Triple Alianza. Algunas tumbas exploradas recientemente apuntan hacia las matanzas masivas en determinadas ocasiones, y las fuentes hablan de multitudinarios sacrificios durante el mes tlacaxipehualistli o en fechas especiales como la entronización de un personaje y la culminación de una obra magnificente. Inclusive, se sostiene que había ofrendas de niños y mujeres según un patrón calendárico (Broda 1971). Pero hay estudios recientes, utilizados más adelante, que esclarecen mejor su significado (ver también bibliografía).

El suceso histórico más citado al respecto es el o los (porque de hecho se construyó en siete o más etapas) sacrificios realizados en el templo de Huitzilopochtli, desde la época de Moctezuma el Viejo y, sobre todo, al inaugurarlo Ahuizotl. Relatan los cronistas, y casi todos coinciden, que en esa consagración Ahuizotl, asesorado por Tlacaelel y con el beneplácito y la participación de los señores de Texcoco y de Tlacopan, salió con anticipación a hacer la guerra para castigar a algunos pueblos que se negaban a pagar el tributo que en conquistas previas se les había asignado. A los apresados se añadieron otros miles que las provincias sujetas entregaron para ser sacrificados. Era tanta sangre -dice Durán- que formó ríos y cuajarones desde lo alto de la escalinata del templo; la pestilencia resultaba insoportable para ellos mismos. Ya que los cuerpos eran virtualmente vaciados y un adulto derrama unos cinco litros de sangre, cien o menos serían suficientes para dar la impresión de arroyos sanguinolentos cubriendo la pirámide.

Varios autores coinciden en que fueron inmolados alrededor de 80.000 en una orgía que duró cuatro días en corrido, aunque también se dice que fueron entre 60 y 80 mil (González 2012: 252) o diez mil o sólo cuatro mil. Las fuentes en que se basa Harner (1977: 119) señalan que fueron 20.000 según el Códice Telleriano-Remensis; 72.344 de acuerdo con Torquemada; 80.400 repiten Ixtlilxóchitl y Durán (1984, II: 345; cap. XLIV § 12); y Sherburne Cook (1946: 91) apunta 20.000 como una «estimación más auténtica y conservadora». No sólo discrepan las cifras sino el destino final de los sacrificados. No todos aducen que fueran para comer, mientras que, para otros, la matanza tuvo lugar frente a «millones de espectadores que tomaron parte en el gigantesco banquete subsecuente» (Graulich 2016: 32).

En función de los datos demográficos de Cook, Harner (1977: 128-129; M. Harris 1989: 298) asume que por año se sacrificaban y comían unas 15.000 almas, un $5 \%$ de la población del Valle, cifra aceptable, insiste, compatible con datos de otras partes. El rango anual variaría entre 10.000 y 250.000 personas (15.000 en promedio, acepta Cook 1946: 93) destinadas a surtir las alacenas de los tenochca por igual.

Una pregunta obligada es hasta qué punto las fuentes reflejan la realidad. El argumento de confiar en ellas porque a fin de cuentas la información se tomó de los propios indios y de sus documentos (González 2010: 397; Graulich 1991: 131) no me parece convincente. Primero: dichas crónicas las escribieron los principales destructores de la religión prehispánica y de la sociedad, y por lo tanto no podían ser objetivos. Describieron con precisión el esplendor de la corte, los edificios, las obras hidráulicas y los mantenimientos, pero en lo tocante a la conquista y la religión se 
guiaron por sus intereses y prejuicios. Segundo: debido a que en la lengua nahua se utilizan muchas metáforas, la ceremonia sacrificial quedó plagada de ellas.

Lo relativo a la exactitud y objetividad de las fuentes se transforma en, por decir lo menos, incongruencias y malos entendidos. La vasta información de los archivos complementa el panorama de numerosos aspectos que soslayaron los escritores del siglo XVI; el problema es que, lo mismo que los tratados clásicos, ésta se toma como verdadera sin analizar el trasfondo, quiénes escribieron y sus motivaciones (Staller 2010: 27-28). Porque las incoherencias sobre el canibalismo y el sacrificio se notan en todas ellas, lo que pone una alerta sobre las generalizaciones. Un buen ejemplo es el de las Relaciones Geográficas, que, sin estar libres de claroscuros, ayudan a evitar conclusiones sesgadas ${ }^{10}$ que a menudo inciden sobre asuntos con repercusiones en nuestra actualidad. Otras disciplinas han contribuido a resolver el atolladero (Freiwald 2010; Howie et al. 2010) sin aportar todavía datos contundentes que lo zanjen. Se han excavado tumbas colectivas que parecen osarios de los desmembrados, aunque sus autores dudan de si los restos eran para comer (Pijoan y Mansilla 2010) o si las estelas son sólo un recordatorio alusivo del sacrificio para lección de las nuevas generaciones (Ladrón de Guevara 2010: 74-75).

\section{Algo sobre las fuentes}

Como muchos estudiosos de la sociedad azteca, Harner (1977: 119) piensa que, para estudiar el problema del canibalismo y las cifras de sacrificados, asuntos eminentemente de carácter político-religioso, las fuentes más confiables (que Caroline Pennock matiza [2012: 280-282]) son Cortés, Díaz del Castillo, Sahagún, Durán y, en menor medida, Torquemada, Zumárraga, Motolinía, Tapia, Acosta, etc., pero no Bartolomé de las Casas. Es decir, se pide aceptar lo que dicen los más acérrimos enemigos (y destructores implacables) de la religión que ellos describen. Esta paradoja ya se había notado (Ortiz de Montellano 1978: 615-616; Castile 1980: 390; Isaac 1983, 2002: 220-221; Reyes et al. 1996: 29-30 y otros), incluso sobre temas menos controvertidos (Coe 2004: 97-98; Staller 2010: 29, 30). Lo anterior nos obliga a mirar con cuidado lo que afirman dichas fuentes, el tiempo, los intereses y fines con que fueron escritas, como también es el caso con quienes lo hacemos hoy. Es, además, momento de recordar que el canibalismo se ha practicado a lo largo de la historia en diversas culturas, incluida la occidental, y que en la mayoría de ellas tiene carácter simbólico; casi en ninguna de sus formas tiene que ver con la necesidad de proteína animal (Lindenbaum 2004). Desde hace tiempo se comprobó que se gasta más energía en cazar a seres humanos, inclusive para engordarlos, que lo que pueden aportar en contenido calórico (Garn 1979).

Dejemos pues de lado por el momento que muchas culturas y sociedades lo hayan hecho o que su práctica azteca haya sido más o menos sanguinaria que en otras. Nuestro afán recae ahora en los números posibles durante la consagración del templo de Huitzilopochtli bajo el reinado de Ahuizotl. Esto ocurrió en 1487, en el mes de tlacaxipehualistli, que iba del 21 de marzo al 9 de abril (Durán) o del 22 de febrero al

\footnotetext{
${ }^{10}$ Barry L. Isaac (2002) analiza 105 Relaciones geográficas, sus objetivos y posibles distorsiones acerca del sacrificio humano. Michel Graulich (2016) profundiza en argumentos, mitos, fuentes, origen y cifras. Su enfoque, como el de Yólotl González (2012), es a favor del canibalismo masivo.
} 
13 de marzo (Sahagún). Fray Diego Durán (1984, II: 344; cap. XLIV, § 7) menciona que los esclavos cautivos por sacrificar formaron cuatro hileras sobre las calzadas de la ciudad: tres de un poco menos de «una legua» y la cuarta, hacia el oriente, hasta donde la laguna lo permitía. En el español del XVI, cuando no se especifica, legua se refiere a las cortas (de aproximadamente $4 \mathrm{~km}$ ), que es el caso en la cita de Durán, pues más adelante al referir otra cuestión, habla de la legua larga, que equivalía a unos $6 \mathrm{~km}$. Es decir, según él, hubo 3 filas de un poco menos de $4 \mathrm{~km}$ cada una (Harris asume por error que eran de $3 \mathrm{~km}, 1987: 148$ ) y la cuarta de un poco más. El Códice Ramírez señala que dichas calzadas medían «dos y tres leguas» (Alvarado Tezozomoc 1980: 95), pero lo que importa es lo que medían las hileras de cautivos. En un metro lineal, pegados entre sí, caben 3 adultos. Si el cálculo de Durán es correcto, cada una estaba formada por unos 8.500 hombres o menos, o alrededor de 32.400 en total.

Durán, Tezozomoc, Alva Ixtlilxóchitl, Acosta y Clavijero repiten casi literalmente la misma fuente: El Códice Ramírez (Alvarado Tezozomoc 1980: 17-149). Aunque no hay acuerdo aceptado, se piensa que fue escrita por un indio en estado secular en la primera mitad del XVI. El nombre nos es desconocido, pero es probable que haya sido alumno de Sahagún en el colegio de Tlatelolco, por lo que se entiende de inmediato su oposición a la religión y orden social antiguos. Si en 1527 y 1529 niños tlaxcaltecas, hoy ya santos declarados (El Universal 15/10/2017), habían increpado a sacerdotes de la antigua religión, denunciado a sus propios familiares como idólatras y tomado acciones para destruir dioses y templos, no hay razón para dudar que otros pequeños nobles, o los mismos principales que se identificaban o colaboraban con los españoles para conseguir o conservar sus privilegios (Rojas, 2016: 145), lavados del cerebro o adoctrinados, no estuvieran dispuestos a escribir en contra de la religión indígena lo que los frailes querían escuchar. Esto pasa incluso ahora, durante el trabajo de campo. En pocas palabras, las cifras que manejan las fuentes parecen una exageración de los frailes que los indios registraron en sus escritos, de donde luego las retomaron otros frailes y cronistas... además de varios investigadores contemporáneos.

Las fuentes concuerdan en que esa fiesta duró cuatro días seguidos y que al quinto los señores enemigos invitados se fueron a sus respectivas tierras ya terminada la consagración. Durán (y otros) menciona que para esa celebración había cuatro altares presididos por Ahuizotl, Nezalhualpilli, Tlacaelel y Totoquiautzin. Que una vez que se cansaban éstos y sus ayudantes eran sustituidos por otros «carniceros», los llama Durán, o «verdugos crueles del demonio», según Motolinía. También dice Durán -y lo hace en específico para esta fiesta-, que el sacrificio humano sólo se llevó a cabo «desde la mañana hasta la puesta del sol» y no día y noche como interpretó Marvin Harris (1989: 300). Es decir, durante unas doce horas de luz o menos, puesto que el festejo se llevó a cabo hacia fines de marzo o principios de abril, cuando el sol sale cerca de las siete y se oculta alrededor de las 18:30 horas.

El ritual no sólo consistía en extraer el corazón de la víctima. Antes de tumbarlo en el ara, era forzado a subir por las escalinatas y muchos presentaban una resistencia feroz, ya que no todos subían con el orgullo en la frente, aunque los tacharan de cobardes. Ya arriba, primero los ataban y detenían por las extremidades (cada una jalada por sendos cuatro ayudantes de quien blandía el cuchillo, mientras un quinto le estiraba la cabeza hacia abajo con una collera para que levantara el pecho), y así el principal ejecutor o verdugo procedía a sacarle el corazón con rapidez, que todavía 
humeante se ofrendaba al sol haciendo una reverencia hacia cada uno de los puntos cardinales. Luego tornaba a embadurnar la estatua y las paredes del templo con la sangre para después deshacerse del cuerpo. Los ejecutores no eran cualesquiera, sino principales de alta jerarquía preparados para el efecto.

Marvin Harris apunta que un cardiólogo moderno estima 20 segundos para extraer el corazón, claro, sin ritual, prolegómenos, resistencia del condenado, subirlo hasta el altar, ofrendar a los dioses, dirigirla a los cinco puntos cardinales, bañar al ídolo en cuestión con la sangre de cada uno, deshacerse del cadáver, arrojarlo por las gradas, etc., parsimonia con la que sí procedían los nahuas. Tal como lo describe Motolinía, el ritual del sacrificio humano debió llevar mucho más tiempo:

«En esta piedra tendían a los desventurados de espaldas para los sacrificios, y el pecho muy tieso, porque los tenían atados de los pies y de las manos, y el principal sacerdote (...) [una vez que acuchillaba a la víctima] daba con el corazón encima del umbral del altar de parte de afuera, y allí dejaba hecha una mancha de sangre (...) y a las veces untaban los labios de los ídolos con la sangre. Los corazones a las veces los comían los ministros viejos; otras los enterraban, y luego tomaban el cuerpo y echábanlo por las gradas abajo a rodar; y llegado abajo, si era de los presos en guerra, el que lo prendió con sus amigos y parientes llevábanlo y aparejaban aquella carne humana con otras comidas, y otro día hacían fiesta y lo comían...

Cuanto a los corazones (...) aquel sacerdote del demonio tomaba el corazón (...) y levantábale como quien lo muestra al sol, y luego volvía a hacer otro tanto al ídolo, y poníasele delante en un vaso de palo pintado (...) y en otro vaso cogía la sangre y daba de ella como a comer al principal ídolo, untándole los labios, y después a los otros ídolos y figuras del demonio» (Benavente 1994: 17-19).

Cito los detalles no por ánimo gore, sino porque cada paso tiene importancia por el tiempo que requiere. Para quien conoce la circunspección de los nahuas y en general de los mesoamericanos, una acción de esta naturaleza parece imposible de completarse en menos de veinte minutos y, ello, con el apuro de terminar una tarea por destajo. Pero extraer el corazón era solo una forma en que ajusticiaban los aztecas: lapidarlos, asaetearlos, arrastrarlos por el cuello con una soga, botarlos al lago, ahogarlos, arrojarlos al fuego, precipitarlos de troncos erigidos para el efecto, etc., eran también actos sacrificiales perpetrados que, tal cual los detallan Eduardo Matos (2010: 52-58) y Yólotl González (2012: 69), no se ligaban con el canibalismo. Así que los que expiraban en el ara es lo que interesa aquí, porque esa ejecución es la que más se ha relacionado con la antropofagia.

Como la fiesta de Huitzilopochtli era la principal en las provincias conquistadas, dice Motolinía que ese día se «sacrificaban de los tomados en guerra o esclavos (...) según el pueblo, en unos veinte, en otros treinta, en otros cuarenta y hasta cincuenta y sesenta; en México sacrificaban ciento, y ahí arriba» (Benavente 1994: 19; Alvarado Tezozomoc [1980: 101] y Durán escriben que podían ser mil).

De nuevo con las cifras de la consagración del Templo Mayor, un cálculo de cinco minutos por sacrificado diría que, en la dicha fiesta, se mataron unos 144 hombres en cada uno de los cuatro altares o 576 en los cuatro durante cada jornada. Unos 2.300 en los cuatro días, cifra inferior a los números que manejan Durán, Alvarado Tezozomoc, Torquemada, Harner y M. Harris. Con todo este ritual, es evidente que, si aumentamos minutos, es decir, a diez, quince o más tiempo por sacrificado, su número se reduce por mitad, a la tercera, cuarta o quinta parte, tiempo de cualquier 
manera insuficiente para ejecutar un sacrificio de acuerdo con la descripción, por ejemplo, de Alvarado Tezozomoc (1980: 95-96), más compleja y completa que la de Motolinía. La mención de Marvin Harris (1989: 300) de 20 segundos por inmolado, daría un total de 34.560 en los cuatro días $(3.600 / 20 \mathrm{~s})$ x (12hrs x 4 altares x 4 días) ${ }^{11}$, o la de Cook (1946: 90-91), de dos o tres minutos para extraer el corazón y los pasos subsecuentes, resultan meras suposiciones.

El argumento sobre el tiempo necesario para cada víctima, más otros cálculos como la capacidad de los tzompantlis, lo había esgrimido Ortíz de Montellano (1983: 403) y concluye que fueron malinterpretados. A más de «contar calaveras» que él midió por el número de las expuestas en el de Tenochtitlan, cuestiona las cifras que, afirma, resultan «físicamente imposibles». Otra duda que surge es que, si las piernas y los brazos se comían por los nobles, las cabezas se colocaban en el tzompantli y los troncos se arrojaban al remolino del lago, cómo aceptar que los sacrificados eran para alimento de sus congéneres antropófagos. Pero en efecto, la cantidad no es lo esencial cuando se quiere explicar el sentido del sacrificio y del canibalismo en el imperio mexica. Independiente del número la pregunta pertinente es ¿qué pasaba con los cautivos de guerra una vez sacrificados? Y, desde luego ¿para qué los mataban? Porque es claro que los tzompantli eran a la vez un despliegue visual disuasivo y una pauta precisa del poderío militar de cada señorío.

\section{De nuevo con los textos}

Hubieran sido 576 o $2.300,15.000$ u 80.400 los inmolados, se presume que todos estaban destinados para consumo humano. Es verdad que prisioneros de guerra y esclavos eran llevados de regreso al corazón del imperio y, que con ciertas dudas, Díaz del Castillo y Cortés testifican acerca de guerreros que comían carne humana en los campos de batalla. Al que llevaban a la ciudad podía ser vendido en los mercados, sobre todo en los de Tenochtitlan o Tlatelolco o reservado para sacrificarlo en la fiesta del gremio o del barrio. En este caso, se le mantenía en la vecindad en que residía quien lo había cautivado y, en varias fiestas del calendario, se le vestía con los ornamentos de un dios específico para ser adorado como su imagen viviente mientras llegaba la fecha de su holocausto. Al final era sacrificado y, una vez muerto, el propietario se llevaba el cuerpo a su casa en donde separaba una pierna para el hueytlatoani y el resto lo compartía con personas de su rango, los llamados «caballeros del sol» que eran los únicos que lo tenían permitido, aunque él no la podía probar. Otras fuentes describen que los cuerpos eran destazados al pie de las gradas (para honrar a Tlaltecuhtli), la cabeza iba al tzompantli. Los brazos y una pierna, ya desmembrados y cocinados se repartían exclusivamente entre los nobles. El otro muslo se enviaba al gran señor. La gente común, o hasta los familiares sin los méritos debidos, no podía probar de este platillo bajo pena de su vida. Y si los más necesitados no tenían acceso a la carne de las víctimas, ¿qué caso tendría para la elite si sus mesas eran servidas con variedad y abundancia?

Con Benavente, Sahagún y Durán surge otro problema. Dominaban el náhuatl, consultaron códices hoy perdidos para siempre, se entrevistaron con ancianos que sobrevivieron a la conquista y los tres investigaron (y participaron de) la cultura

\footnotetext{
${ }^{11}$ Con 20 minutos, las cifras serían ( $12 \mathrm{hrs}$ luz x $60 \mathrm{~min} \times 4$ aras $\times 4$ días $) / 20 \mathrm{~min}=576$ en total.
} 
nahua. Sahagún contó sobre todo con la ayuda de jóvenes recién convertidos a la fe católica. Es decir, nada se les puede pedir o cuestionar acerca de su metodología ni su mirada religiosa demerita el considerar a éste como padre de la antropología mexicana. No obstante, a más de los prejuicios que los tres compartían -por ejemplo, que había que entender la religión azteca (y la cultura) para saber mejor cómo destruirlas (a lo cual contribuyeron con un ardor tesonero y un empeño destructor fuera de toda duda) o que la religión, sobre todo la nahua, fue inspirada e instigada por el diablo-, de manera quizá inconsciente falsificaron o distorsionaron los hechos de acuerdo a sus prejuicios, y lo paradójico es que los indios los repitieron guiados por tales enseñanzas.

En un artículo sobre los nativos del bosque tropical en el noreste de Australia, David Harris (1987: 369) y antes Marvin Harris, en Caníbales y reyes (1987: 141), anotan que en esas sociedades tribales del siglo XIX se encuentra el núcleo del sacrificio humano ritual y del canibalismo igual que entre las de Canadá, Estados Unidos, el Amazonas y en otras épocas y partes del mundo (Fernández-Armesto 2004: 56-59; Calavia 2009; Graulich 2016: 19-22). Varios grupos americanos cautivaban a los enemigos, a menudo los agasajaban con comida y mujeres antes de sacrificarlos, a veces los torturaban para luego matarlos y cocinarlos. Así que la hipótesis acerca de la pervivencia de la antropofagia en sociedades estatales ayuda a establecer paralelismos entre lo que ocurría con sociedades sin Estado y los mexica, pero no sirve de mucho porque los aztecas conformaban una sociedad clasista, amplia y rigurosamente estratificada, con un Estado fuerte y autoritario.

\section{Contradicciones e inconsistencias de los cronistas}

Que la esclavitud y el sacrifico humano fueran asuntos reglamentados por el Estado mexica y no expiaciones poco dice de su posible conexión con la guerra, la ingesta de carne humana (sea en forma ritual o no), la disponibilidad de los recursos animales y la comida cotidiana hacia el tiempo de la conquista. Esta situación, la referida a la alimentación diaria, sin dejar de ser desfavorable para los campesinos pobres, no era homogénea en toda Mesoamérica (Ruvalcaba 2017). En este caso las fuentes etnohistóricas son insuficientes para esclarecer el asunto del canibalismo porque testimonios abundan a favor y en contra (Calavia 2009: 47) y aun los datos aportados por la paleontología o la antropología física sugieren explicaciones que no implican el sacrificio ni la antropofagia (Isaac 2002: 219-221). Dadas las afirmaciones irreconciliables de los cronistas, soldados, funcionarios y demás, un par de ejemplos bastarán para ilustrar la diversidad.

Cortés habla acerca de indios caníbales cuando acicateado por la codicia, trataba de atenuar sus desmanes y conseguir privilegios del rey (Castile 1980: 82; González 2012: 75). Pero sus falacias son evidentes. O, ¿cómo creerle si desembarcado recién en las costas de la península de Yucatán, puede afirmar, «hemos sabido y hemos sido informados de cierto que todos son sodomitas»? (Cortés 1963: 25). O que él (pág. 24) y otros de sus soldados vieron que cada día los indios sacrificaban cuatro o cinco muchachos, cifra que repite y adorna Bernal ${ }^{12}$, es decir, entre 1500 y 1800 en cada

\footnotetext{
${ }^{12}$ De su paso por Cempoala dice el soldado cronista: «... y cada día sacrificaban delante de nosotros tres o cuatro o cinco indios (...), y cortábanles las piernas y los brazos y muslos, y lo comían como vaca que se trae de las carni-
} 
«mezquita» por año, que el primero no dice, pero sí Bernal (1976: 74, cap. XLIV) que eran para comer. Porque según Carolyn Freiwald (2010), en los asentamientos mayas que excavó, todos los huesos encontrados en un lapso que va desde antes de Cristo hasta el clásico tardío pertenecen a venados, tortugas, tapires y otros mamíferos, aves o reptiles y sólo uno a un ser humano.

En su primera estancia en Tenochtitlan, Cortés interfirió en asuntos imperiales de envergadura y con libertad pudo vagar por la ciudad (al menos dentro de los palacios y templos más importantes) según sus deseos, pero apenas menciona sacrificios o festines caníbales. Lo anterior no fue por falta de percepción puesto que sí pudo observar y describir con bastante precisión la imagen de Huitzilopochtli (1963: 75), hecha de semillas de amaranto, miel y sangre proveniente de los auto sacrificios, que no era algo evidente a simple vista ni a los ojos de los no iniciados.

Si Cortés buscaba defender la conquista, el saqueo y la rapiña como era su pretensión, es curioso que casi no mencionara el canibalismo en su primera estancia, ya que dicho argumento junto con el paganismo o la herejía (no ser católico), la homosexualidad y la blasfemia (Fernández-Armesto 2004: 52), era lo que mayor peso tenía ante los ojos europeos del momento para hacer la guerra ${ }^{13}$. De hecho, Cortés alega el canibalismo apenas en la segunda carta, después de haber vivido desde fines de noviembre de 1519 hasta principios de julio de 1520 y luego de ser sacado por las armas de Tenochtitlan. Él escribe (1963: 104) desde Tepeaca o Segura de la Frontera en octubre de 1520: «... hice ciertos esclavos [en Tepeaca], de que se dio el quinto real a los Oficiales de Vuestra Majestad: porque, demás de haber muerto a los dichos [diez] españoles, y rebelándose contra el servicio de Vuestra Alteza, comen todos carne humana», como si los campesinos pudieran disfrutar de semejantes manjares. Más bien, Cortés echó mano de la trillada fórmula para esclavizar a personas libres sin tener que explicar más sus actos, tal cual había hecho Colón en su segundo viaje y, después, otros españoles tanto en las Islas del Caribe como en el continente. Como señala Sophie D. Coe, «el canibalismo [fue] la vara perfecta para golpear a los indígenas y muchos europeos la tomaron y elaboraron con ella historias aprovechándola en todo su valor» (Coe 2004: 149). Hay otros ejemplos contradictorios o confusos.

Sobre la subsistencia, Cortés señala (1963: 23) que los indios en la península de Yucatán tenían como mantenimientos al «maíz y algunos ajís como los de las otras islas y patata yuca (...) y tienen sus pesquerías y cazas, y crían muchas gallinas como las de Tierra Firme, que son tan grandes como pavos». En éste, como en otros lugares donde estuvieron los españoles había abundancia de comidas, campos de cultivo y tributos que a veces les ofrecían los nativos o ellos simplemente los pillaban. En Tenochtitlan, la riqueza y la abundancia que observaron Cortés, Bernal, Motolinía y varios más reflejan un panorama que para nada coincide con un ambiente degradado. Enorme fue su sorpresa cuando visitaron los grandes mercados, que por su afluencia e intensidad en el intercambio es una de las características de la civilización mesoamericana. Aun en Tlaxcala, donde los mercaderes no podían salir de la provincia para obtener algodón o sal, cada día se congregaban 30.000 personas o más, para comprar y vender, sin contar los otros «mercadillos que hay por la ciudad en partes»

cerías en nuestra tierra, y aun tengo creído que lo vendían por menudo en los Tiangues, que son mercados» (1976: 87, cap. LI).

${ }^{13}$ Shirley Lindenbaum (2004) sintetiza los tipos de canibalismo, lugares en donde se ha practicado y los cambios en su concepción entre los europeos, del siglo XIV al XVIII, hasta convertirse en falta abominable propia de los salvajes, a quienes obviamente ellos tenían que civilizar. 
(Cortés 1963: 45). En Tenochtitlan en el mercado diario se reunían hasta 60.000 almas.

Más exageraciones de Cortés, o hasta mentiras, pueden detectarse con facilidad, como cuando 400 españoles que nada o muy poco sabían del territorio ni de sus recovecos, ayudados por «la voluntad de Dios», pudieron vencer a 40.000 indios (Cortés 1963: 18). O, en su camino a Tlaxcala, 300 españoles con 13 caballos y 40 ballesteros, rodeados de enemigos, pudieron derrotar en un día a 100.000 indios guerreros y en la mañana siguiente a otros casi $150.000^{14}$.

De Bernal se sabe que terminó sus memorias a la edad de 73 años y muchas cosas, como admite en toda honestidad, él sólo las oyó decir. Algunas veces las trata como si fueran verdad, pero sus lectores acríticos las toman como verdades absolutas. Todavía se discute acerca de si sus escritos son historia, ficción o si él es el autor, que yo doy por hecho igual que otros autores (Martínez 2013). Cuenta haber visto cinco hombres que «estaban abiertos por los pechos y cortados los brazos y los muslos, y las paredes (...) llenas de sangre» (1976: 24, cap. XIII), pero no dice que fueran para comer. Y tierra adentro, menciona el sacrificio de entre tres y cinco adultos por día, igual que Cortés, y describe los tzompantlis desde su desembarco en la costa del Golfo, por los pueblos que atravesaban, sin excepción. Sobre el canibalismo dice creer que comían y vendían parte de los sacrificados, cuando muchos de los grupos costeros no consumían carne humana. Es él quien menciona las jaulas para engordar a los reclusos destinados a la olla (1976: 92, cap. LIV) y repite Graulich (2016: 227), aunque Durán deja en claro que las dichas jaulas eran prisiones y no celdas para cebarlos y que, en general, los presos presentaban un tal estado de desfallecimiento, hasta quedar en «los puros huesos». En pocas palabras, Díaz del Castillo parece preciso en algunas cosas (Cook 1946: 88-89), en otras, confundido y en otras más simplemente las exagera (Rivero 2011). Pero la justificación estaba en el aire y después la soldadesca, los encomenderos y muchos colonos la repetían como fórmula eficaz, pero totalmente gratuita.

Como pasa con Cortés y Bernal, las fuentes consultadas por Sahagún, Durán y otros tampoco están libres de contradicciones. Para apuntar sólo dos, cuando en el Códice Ramírez leemos que Tlaxcala, Huejotzingo, Huauquechula, Tepeaca, Cholula, Atlixco y otras provincias no pagaban tributo porque los mexica no querían someterlas para así tener lugares cercanos desde donde traer cautivos, es difícil tomarlo de manera literal. Otros testimonios concuerdan en que los aztecas no pudieron someterlos. Antes de la conquista, no menos de cinco veces, los aztecas fueron derrotados o bien salieron empatados en sus guerras contra tlaxcaltecas y tarascos (Cortés 1963: 44; Torquemada 1975, I: 219; lib. $2^{\circ}$, cap. LXXXII. Alvarado Tezozomoc 1980: 75 y Durán 1984, II: 283-284; cap. XXXVII, § 14-18 sobre Michoacán). La vanagloria de las conquistas registradas por los mexica parece más un ideal al que aspiraban (y esto nada les quita de su enorme poderío) que una realidad ya concreta y permanente. No es congruente que tantas veces se fuera a sojuzgar la misma provincia. Si suponemos una situación derivada de sus propias crónicas, es probable que las provincias

\footnotetext{
${ }^{14}$ Relata Cortés (1963: 41): «... nos llevaron peleando hasta nos meter, entre más de cien mil hombres (...) que por todas partes nos tenían cercados, y peleamos con ellos, y ellos con nosotros, todo el día hasta una hora antes de puesto el sol (...) en que con media docena de tiros de fuego y con cinco o seis escopetas y cuarenta ballesteros y con los trece de caballo (...), les hice mucho daño sin recibir de ellos ninguno (...) Bien pareció que Dios fue el que por nosotros peleó, pues entre tanta multitud (...) y tan animosa y diestra en el pelear, y con tantos géneros de armas para nos ofender, salimos tan libres».
} 
tributarias entregaran lo tasado el año de su derrota, quizá durante unos pocos más y luego dejaran de pagarlo hasta que eran de nuevo dominados. Por lo visto, el Códice Mendocino y La Matrícula de Tributos reflejan el ideal mexica de cómo debiera ser el mundo y cómo repartirlo. O, también, que uno y otro desplieguen lo que llegaba desde las provincias tanto por tributo como por comercio.

Otro lío está relacionado con la preparación y el paso de los ejércitos aztecas para sujetar algún grupo o señorío. Las fuentes señalan las grandes cantidades de provisiones que se cargaban, sobre todo en el viaje de vuelta. A todos los pueblos tributarios por los que cruzaban en ambos sentidos los obligaban a entregar comida en abundancia $\mathrm{o}$, si no, los guerreros aztecas la tomaban por la fuerza -como hacían los soldados hispanos- además de destruir milpas y casas en represalia por la negativa. Es decir, comida había sin cautivos ni todavía capturar los pueblos.

Una suposición errónea más se ha asumido con respecto al destino de los cuerpos luego de arrojarlos pirámide abajo. Basado en Díaz del Castillo, Harner (1977: 120) afirma que los animales carnívoros del zoológico se alimentaban con el tronco de los sacrificados ya separados el corazón, la cabeza, piernas y brazos ${ }^{15}$. En sentido contrario, Cortés afirma (1963: 78; Coe 2004: 145) que pájaros de presa, víboras, felinos y predadores sólo comían guajolotes, cuantos era menester. Torquemada (1975 I: 298; lib. $3^{\circ}$, cap. XXV) confirma que a los carnívoros del zoológico se les alimentaba con más de 500 guajolotes al día, pero nada de carne humana. Durán, quien más menciona los miles de sacrificados para ser comidos, deja en claro que era obligación de los sacerdotes arrojar los troncos en el remolino del lago.

A pesar de las distorsiones de las fuentes, no se puede negar el sacrificio humano entre los aztecas, que, sostengo, era una advertencia de lo que les pasaría a las provincias que se negaban a tributar al imperio y a los aliados si lo dejaban de pagar. Los sacrificios en las pirámides, de manera pública o secreta, eran una ejecución de enemigos políticos del Triple Imperio, que se contaban por millones, esclavos, criminales, delincuentes y otros. Eran una forma de enterar a los aliados y a los enemigos que pagaran tributo y, para los locales, exhortarlos a no delinquir ni quebrantar el orden establecido. Lo anterior explica también por qué se invitaba a gobernantes amigos, enemigos y de los señoríos independientes a presenciarlos, so pena de ser «sacrificados como los esclavos» (Alvarado Tezozomoc 1980: 321). O que a los prisioneros lo hicieran trabajar en obras públicas, construcción de templos, apertura de canales y calles y, a los que vendían su libertad, como vasallos domésticos o agrícolas hasta que la compraban de nuevo.

En suma, la «muerte al filo de obsidiana» entre los aztecas, como ejecución de Estado, estaba reservada para la pléyade de enemigos políticos, los considerados delincuentes contumaces, ciertos esclavos y algunos otros del pueblo común. Si los mexica eran rigurosos en sus castigos no eran excepcionales cuando vemos el número de naciones en guerra, las que aplican la pena de muerte o, en esa época, siglo XVI, el trato que se les daba a los disidentes religiosos en diversos países de

\footnotetext{
15 Prosigue Bernal (1976: 169, cap. XCI): «... vamos a otra gran casa donde tenían (...) sus dioses bravos, y con ellos todo género de alimañas, de tigres y leones de dos maneras (...) adives [coyotes] y zorros (...) y todas estas carniceras (...) las daban de comer venados, gallinas, perrillos y otras cosas que cazaban; y aun oí decir que cuerpos de indios de los que sacrificaban (...) y el cuerpo del sacrificado no llegaban a él para comerle, sino dábanlo a aquellos bravos animales». Harner traduce las palabras de Díaz del Castillo «y aun oí decir» por como «fui dicho», lo que altera el grado de veracidad.
} 
Europa $^{16}$. Si eran severos contra de la disidencia política, el crimen y el vicio resulta injusto calificarlos de carniceros que mataban gente sin sentido «sólo para obtener una pieza de carne» o por la frecuencia de los sacrificios «extremadamente» numerosos durante el ciclo anual. Aparte de no tener información contundente, con la que contamos, llena de prejuicios y exageraciones, no coincide con estos festines de «víctimas humanas, que a veces se contaban por miles» (Graulich 2016: 134, 261). Otros episodios confirman dicha injusticia.

Cuando el sitio y asedio final de Tlatelolco-Tenochtitlan por Cortés y sus huestes indias aliadas, se describe a los sitiados como gente hambrienta y sin víveres (Alvarado Tezozomoc 1980: 367-369; cap. XL. La nota 1 recuenta lo que dicen los propios testigos). Y aunque los cadáveres de tenochcas y sus enemigos se apilaban a lo largo de casas y calles, ningún cuerpo era tocado ni mucho menos comido. Por lo demás, valdría preguntar a un matado o a sus deudos si encuentran diferencia entre expirar acuchillados en una pirámide, en el circo romano, en la cruz, por una inyección letal, una descarga eléctrica, ahorcados, de un balazo en la nuca o, peor aún, torturado, gaseado, fusilado, degollado o rostizado sin saber por qué, o por sus puras creencias.

En otro ámbito, ¿qué debemos entender como un área circunscrita? Si se atiende a las exageradas cantidades de tributo y mercancías que llegaban no es posible tal clasificación para el Valle de México. Sus pueblos no eran autárquicos ni autosuficientes pero no estaban aislados. Sus redes comerciales y tributarias lo hicieron abierto, dinámico, como reflejan los abastecidos mercados que, desde sus inicios, son un rasgo distintivo de todas sus culturas.

\section{Colofón}

Como se puede inferir, sobre el canibalismo hay indicios tomados como testimonios categóricos que apenas llegan a deducciones o ficciones tanto de aquellos tiempos como de hoy día. En cuanto a las interpretaciones, está demostrado que no estuvo relacionado con la necesidad de proteína animal (Ortiz de Montellano 1978, 1983: 403) ni con la guerra en sí misma. No es posible cuadrar los números de las fuentes ni tomar ese rasgo como central de la cultura azteca. Tampoco es razonable retratar la sociedad tenochca apabullada por el terror a sus gobernantes, como hacen algunos autores pues, como símiles, tampoco lo sería afirmar que la sociedad española medieval, completa, vivía en la paranoia por los horrores de la inquisición o que todos los alemanes y países conquistados, incluso los colaboradores, actuaron por miedo de las atrocidades nazis. De las crónicas novohispanas no se desprende la primera imagen, sino que la empresa central del Imperio Azteca -y la de sus predecesoresera asegurar cantidades enormes de tributos de manera estable, que incluían todo tipo de bienes y mercancías, de lujo o comunes y corrientes por medio de la religión, el militarismo y la conquista. Asociar sacrificio humano y canibalismo resultó una excusa idónea que se utilizó y repitió desde los primeros viajes europeos cuando, y sólo cuando, los nativos se negaban a acceder a las demandas o desmanes de los hispanos.

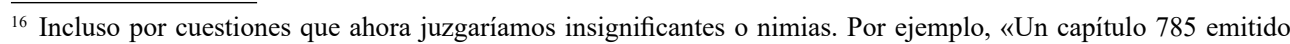
en y para Sajonia, castigaba el quebrantamiento de la Cuaresma con la muerte, a menos que el consumo de carne haya sido compelido por el hambre» (Pearson 1997: 9).
} 
Si el sacrificio humano era parte de la cultura mesoamericana (Olivier y López Luján 2010) la antropofagia como fuente de alimento no lo fue. Guerras y sacrificios no buscaban surtirse de proteína animal, que obtenían de otros recursos hasta los no privilegiados (Coe 2004, cap. V; Parsons 2010; Santley y Rose 1979: 193-195).

Sin duda, crónicas, archivos y códices guardan una riqueza de datos de obligada consulta para entender las culturas prehispánicas y su transformación colonial o herencia actual. Incluso, en temas tan controvertidos seguirán como guía, pero no servirán mucho para explicar si había o no antropofagia ni de sus objetivos de ser el caso. Ahora se cuenta con más valoraciones e interpretaciones de las crónicas y de la conquista ${ }^{17}$, así como de otros recursos científicos que detallan la composición de las dietas, porcentaje de plantas o carnes consumidas y hasta de qué fuente provenían los aminoácidos. Seguirán pues los debates serios (Escalante y Martínez 2010) y absurdos ${ }^{18}$ y serán otras disciplinas como la paleontología, los análisis de isótopos, de coprolitos con sus nuevas técnicas las que podrán esclarecer este asunto (Freiwald 2010; Howie et al. 2010). Lo anterior, como digo, no quita valor a las crónicas, documentos de archivo, la iconografía, etc., pero en definitiva sobre este asunto, si no han dicho su última palabra, exigen de una mirada crítica y rigurosa. Guardan todavía sorpresas, comentó Luis Reyes en una charla, como uno de los expedientes en que se lee que sacrificaron a un infante, y al día siguiente el mismo indica que el chiquillo correteaba por el patio de la casa. Según su interpretación, se trataba de un mero sacrificio simbólico.

Siguiendo a Sahagún cuando habla de la mesa de Moctezuma, las palabras de Torquemada podrían aplicarse a toda la nobleza azteca:

«Algunas veces (aunque pocas) [Moctezuma] comía Carne Humana, pero esta avía de ser de la sacrificada, y aderezada, mui por estremo, y de otra manera no la comía ${ }^{19}$, como quisieron, falsamente, imputarle algunos [españoles], que ni lo supieron, ni entendieron, sino por mala voluntad, que les tenían concebida á los Indios» (Torquemada 1975, I: 229; lib. $2^{\circ}$, cap. LXXXVIII).

Esta «mala voluntad» se presenta con tanta o más fuerza en la actualidad. A algunos componentes habituales de la dieta de los mexicanos, la famosa triple T: tacos, tortas y tamales (más otras dos: tortillas y tostadas), se le achaca ser causantes de la obesidad, diabetes, alta presión, altos niveles de colesterol, triglicéridos y otras enfermedades hoy comunes en México cuando en verdad son provocados por los hábitos aberrantes de la mala nutrición. Esta publicidad negativa la promueven y alientan las trasnacionales alimenticias, cuyos productos sí que son comida chatarra y aun así ni cesan ni cejan en promoverla y venderla, con el contubernio de autoridades y publicistas, y el añadido cínico de «come frutas y verduras y haz ejercicio». Basta ver de qué está hecho cada uno. Análisis imparciales comprueban que una «quesadilla» de flor de calabaza es más nutritiva que un sándwich de pan blanco; que una torta al estilo mexicano contiene los componentes de un buen régimen ali-

\footnotetext{
${ }^{17}$ Su evaluación crítica queda fuera de los objetivos de estas líneas, pero no puedo dejar de recomendar los textos de Livi Bacci (2006), Restall (2005), Ortiz de Montellano (1990) y otros que ofrecen interpretaciones tanto globales como sobre aspectos o grupos particulares.

${ }^{18}$ Inga Clendinnen (1991) y, en otro nivel, la diatriba de José Antonio Sánchez, presidente de RTVE, quien admite que «Lamentar la desaparición del Imperio azteca es como mostrar pesar por la derrota de los nazis en la Segunda Guerra Mundial» (El País, 5/04/2017; La Jornada, 6/04/2017).

${ }^{19}$ Por el contrario, Sophie Coe señala que Moctezuma la comía sin condimentar, incluso sin sal.
} 
menticio: carbohidratos, proteínas y vitaminas. Los atoles y jugos de fruta no tienen comparación con las bebidas gaseosas embotelladas. Los tamales, además de un signo de identidad (Pilcher 2001), pueden rellenarse de 100 o más maneras, tal sea la inventiva de quien los cocina. Si no son los originales porque cualquier «comida típica»: pozole, mole, atoles, chocolate... contiene migas prehispánicas, europeas o asiáticas, ello no los hace menos apetecibles, sino que la combinación incrementó su valor nutritivo y su aceptación.

Al respecto, recuerdo una entrevista con Luis Valdez, director de la película Zoot Suit, en la que ironizaba que mientras un sándwich se prepara sin mayor miramiento que emparedar una tajada de jamón o queso en dos rebanadas de pan, un taco implica que la mamá prepare el guiso, lo enrolle en una tortilla, piense en varios platillos y escoja el preferido de sus hijos; un tentempié elaborado con cariño y amor. Así sea un tanto idealizado, de verdad hay diferencia en la preparación y el contenido nutritivo a favor del taco, la quesadilla, la torta o el atole. Una torta tiene frijol, aguacate, jitomate, cebolla, picante, rellena de carne, queso, lechuga, y el pan, integral o blanco. Igual que un taco, cuya envoltura, la tortilla, es recién hecha, caliente y fresca. Nada que ver con el pan almacenado por semanas o meses en el súper o en el refrigerador. Si extranjeros y nacionales pescan la venganza de Moctezuma, ello tiene que ver con la higiene de los alimentos y de quienes los preparan, como en todas partes del mundo.

Sobre la época prehispánica, hoy sabemos que los macehuales (y nobles) del Valle de México tenían acceso a una cantidad enorme de aves, algas, frutas, hongos e insectos que, de sobra, pueden satisfacer las necesidades nutricionales requeridas por los humanos (López Riquelme 2010; Parsons 2010; Ramos-Elorduy 1987). Si para muchos su consumo es inconcebible, existen otros juicios de valor con respecto a los vacunos, insectos y demás bichos como pasa entre los grupos de Amazonas, Borneo y África (Dufour 1978: 394). Lo que resalta es que las acusaciones de canibalismo lo mismo que achacar las enfermedades sociales a la dieta actual más popular de los mexicanos son inducción de intereses, prejuicios culturales que a base de repetición masiva se dan por ciertos. El prejuicio extremo es que, si los prehispánicos no comían vaca, cerdo, pollos, entonces se comían a sus congéneres. El perjuicio es que admitimos el «si no comes como nosotros no eres civilizado», traducido en que si no consumimos pan, leche, carne y huevos entonces maíz, frijoles y chile no nos alimentan como es debido y de allí nuestro subdesarrollo económico, físico y mental. Ahora han aparecido estupendos trabajos sobre dietas y alimentos que por espacio sólo puedo referir y esbozar lo que comían nuestros antepasados $^{20}$. Estas líneas prueban que el sacrificio en Mesoamérica no era para cubrir las necesidades de carne y grasa animal y hacen constar el riesgo de tomar al pie crónicas o estudios actuales. Si la hay, la última palabra provendrá de otras disciplinas y cabezas, espero.

Sólo un punto más. Etiquetas como negacionista, revisionista o canibalista no ayudan, sino que impiden entender las sociedades prehispánicas. La religión y el sacrificio, en especial de mayas y aztecas, se han estudiado hasta el último pliegue: calendario festivo, dioses asociados, sus variados nombres, alias, máscaras y adornos; los sacerdotes que les servían, sus atavíos, conducta e influencia social. Se ha

\footnotetext{
${ }^{20}$ Las dietas más comunes en Europa y Mesoamérica del siglo XVI las trato a detalle en Ruvalcaba (2017). Se puede acudir a Charles Gibson, Sophie Coe, Jeffrey Parsons y Santley y Rose, citados más arriba, así como al libro de Bernardo Ortiz de Montellano (1990).
} 
descrito con minucia su proceder en la inmolación, las acciones consecutivas y el ritual que los rodeaban. Vamos, hasta el material y el tamaño del navajón con el que abrían a los ajusticiados. No sorprende que los escritores del siglo XVI se concentraran en esos temas y dejaran de lado, por obvia y ser cosa del «común», la actividad sustantiva. Pero los autores modernos no debiéramos girar en torno a la misma noria. Si con parecido esmero y pasión estudiáramos la agricultura prehispánica (sobre la que hay excelentes trabajos pero en comparación muchos menos), se entenderían mejor esas sociedades, que testigos de la época y estudiosos modernos, aunque sólo referida en ocasiones, todos sin excepción, y con esto termino, admiten que para la religión, el calendario, la guerra, en suma, para el desarrollo mesoamericano, fue la base común y mayoritaria.

\section{Referencias}

Albornoz, Rodrigo de. 1980 (1525). «Carta del contador Rodrigo de Albornoz, al Emperador», en Colección de documentos para la historia de México, Joaquín García Icazbalceta, ed., tomo I, pp. 484-511. México: Librería de J. M. Andrade.

Alvarado Tezozomoc, Hernando. 1980. Crónica Mexicana, escrita por (...) hacia el año MDXCVIII (...) y precedida del Códice Ramírez (...) México: Editorial Porrúa.

Benavente, Fray Toribio de (Motolinía). 1914. Historia de los indios de la Nueva España. Barcelona: Herederos de Juan Gili. Biblioteca Digital Hispánica, http://bdh.bne.es/ bnesearch/detalle/bdh0000102364.

—. 1994. Relaciones de la Nueva España. México: Universidad Nacional Autónoma de México.

Broda de Casas, Johanna. 1971. «Las fiestas aztecas de los dioses de la lluvia». Revista Española de Antropología Americana 6: 245-327.

Calavia Sáez, Óscar. 2009. «O canibalismo asteca: releitura e desdobramentos». Mana 15 (1): 31-57.

Carrasco, David. 1995. «Cosmic Jaws: We Eat the Gods and the Gods Eat Us». Journal of the American Academy of Religion 63 (3): 429-463.

Castile, George Pierre. 1980. «Purple People Eaters?: A Comment on Aztec Elite Class Cannibalism à la Harris-Harner». American Anthropologist 82 (2): 389-391.

Clendinnen, Inga. 1991. «Fierce and Unnatural Cruelty’: Cortés and the Conquest of Mexico». Representations 33: 65-100.

Coe, Sophie D. 2004. Las primeras cocinas de América. México: Fondo de Cultura Económica.

Cook, Sherburne F. 1946. «Human Sacrifice and Warfare as Factors in the Demography of Pre-Colonial Mexico». Human Biology 18 (2): 81-102.

Cortés, Hernán. 1963. Cartas y documentos. México: Editorial Porrúa.

Díaz del Castillo, Bernal. 1976. Historia verdadera de la conquista de la Nueva España. México: Editorial Porrúa.

Dufour, Darna L. 1987. «Insects as Food: A Case Study from the Northwest Amazon». American Anthropologist 89 (2): 383-397.

Durán, Fray Diego. 1984. Historia de las Indias de Nueva España e Islas de la Tierra Firme, 2 tomos. México: Editorial Porrúa.

Escalante Gonzalbo, Pablo y Rodrigo Martínez Baracs. 2010. «Sacrificio y antropofagia». Letras Libres 133: 16-22. 
Fernández-Armesto, Felipe. 2004. Historia de la comida. Alimentos, cocina y civilización. Barcelona: Tusquets.

Freiwald, Carolyn R. 2010. «Dietary Diversity in the Upper Belize River Valley: A Zooarchaeological and Isotopic Perspective», en Pre-Columbian Foodways. Interdisciplinary Approaches to Food, Culture, and Markets in Ancient Mesoamerica, John E. Staller y Michael Carrasco, eds., pp. 399-420. Nueva York: Springer.

Garn, Stanley M. 1979. «The Noneconomic Nature of Eating People». American Anthropologist 81 (4): 902-903.

Gibson Charles. 1967. Los aztecas bajo el dominio español (1519-1810). México: Siglo XXI.

González Torres, Yólotl. 2010. «El sacrificio humano: poder y sumisión», en El sacrificio humano en la tradición religiosa mesoamericana, Leonardo López Luján y Guilhem Olivier, coords., pp. 397-406. México: Instituto de Investigaciones Históricas, UNAMInstituto Nacional de Antropología e Historia.

—. 2012 (1985). El sacrificio humano entre los mexicas. México: Fondo de Cultura Económica-Instituto Nacional de Antropología e Historia.

Graulich, Michel. 1991. «L'inauguration du temple principal de Mexico en 1487». Revista Española de Antropología Americana 21: 121-143.

—. 2016 (2005). El sacrificio humano entre los aztecas. México: Fondo de Cultura Económica.

Harner, Michael. 1977. «The Ecological Basis for Aztec Sacrifice». American Ethnologist 4 (1): 117-135.

Harris, David R. 1987. «Aboriginal Subsistence in a Tropical Rain Forest Environment: Food Procurement, Cannibalism, and Population Regulation in Northeastern Australia», en Food and Evolution. Toward a Theory of Human Food Habits, Marvin Harris y Eric B. Ross, eds., pp. 357-385. Filadelfia: Temple University Press.

Harris, Marvin. 1987. Caníbales y reyes. Los orígenes de las culturas. Madrid: Alianza Editorial. . 1989. Bueno para comer. Enigmas de alimentación y cultura. México: ConacultaAlianza Editorial.

Howie, Linda, Christine D. White y Fred J. Longstaffe. 2010. «Potographies and Biographies: The Role of Food in Ritual and Identity as Seen through Life Histories of Selected Maya Pots and People», en Pre-Columbian Foodways. Interdisciplinary Approaches to Food, Culture, and Markets in Ancient Mesoamerica, John Edward Staller y Michael Carrasco, eds., pp. 369-398. Nueva York: Springer.

Ingham, John M. 1984. «Human Sacrifice at Tenochtitlan», Comparative Studies in Society and History 26 (3): 379-400.

Isaac, Barry L. 1983. «Aztec Warfare: Goals and Battlefield Comportment». Ethnology 22 (2): 121-131.

. 2002. «Cannibalism among Aztecs and Their Neighbours: Analysis of the 15771586 ‘Relaciones Geográficas’ for Nueva España and Nueva Galicia Provinces». Journal of Anthropological Research 58 (2): 203-224.

Ladrón De Guevara, Sara. 2010. «El sacrificio humano en la costa del Golfo», en El sacrificio humano en la tradición religiosa mesoamericana, Leonardo López Luján y Guilhem Olivier, coords., pp. 67-77. México: Instituto de Investigaciones Históricas, UNAMInstituto Nacional de Antropología e Historia.

Lindenbaum, Shirley. 2004. «Thinking about Cannibalism». Annual Review of Anthropology 33: 475-498.

Livi Bacci, Massimo. 2006. Los estragos de la conquista. Quebranto y declive de los indios de América. Barcelona: Crítica. 
López Riquelme, Germán. 2010. Xopamiyolcamolli. Gastronomía de bichos con muchas patas. México: Imprenta Grafimex.

Martínez Baracs, Rodrigo. 2013. «¿Bernal o Cortés?». Letras Libres 174: 28-34.

Matos Moctezuma, Eduardo. 2010. «La muerte del hombre por el hombre: el sacrificio humano», en El sacrificio humano en la tradición religiosa mesoamericana, Leonardo López Luján y Guilhem Olivier, coords., pgs. 43-64. México: Instituto de Investigaciones Históricas, UNAM-Instituto Nacional de Antropología e Historia.

Olivier, Guilhem y López Luján, Leonardo. 2010. «El sacrificio humano en Mesoamérica», en El sacrificio humano en la tradición religiosa mesoamericana, Leonardo López Luján y Guilhem Olivier, coords., pp. 19-42. México: Instituto de Investigaciones Históricas, UNAM-Instituto Nacional de Antropología e Historia.

Ortiz de Montellano, Bernard R. 1978. «Aztec Cannibalism: An Ecological Necessity?». Science 200, 4342: 611-617.

-1983. «Counting Skulls: Comment on the Aztec Cannibalism Theory of HarnerHarris». American Anthropologist 85 (2): 403-406.

1990. Aztec Medicine, Health, and Nutrition. New Brunswick: Rutgers University Press.

Parsons, Jeffrey R. 2008. «Beyond Santley and Rose (1979): The Role of Aquatic Resources in the Prehispanic Economy of the Basin of Mexico». Journal of Anthropological Research 64 (3): 351-366.

- 2010. «The Pastoral Niche in Pre-Hispanic Mesoamerica», en Pre-Columbian Foodways. Interdisciplinary Approaches to Food, Culture, and Markets in Ancient Mesoamerica, John E. Staller y Michael Carrasco, eds., pp. 109-136, Nueva York: Springer.

Pearson, Kathy L. 1997. «Nutrition and the Early-Medieval Diet». Speculum 72 (1): 1-32.

Pennock, Caroline Dodds. 2012. «Mass Murder or Religious Homicide? Rethinking Human Sacrifice and Interpersonal Violence in Aztec Society». Historical Social Research 37 (3): 276-302.

Pijoan Aguadé, Carmen María y Josefina Mansilla Lory. 2010. «Los cuerpos de sacrificados: evidencias de rituales», en El sacrificio humano en la tradición religiosa mesoamericana, Leonardo López Luján y Guilhem Olivier, coords., pp. 301-316. México: Instituto de Investigaciones Históricas, UNAM-Instituto Nacional de Antropología e Historia.

Pilcher, Jeffrey M. 2001. ¡Vivan los tamales! La comida y la construcción de la identidad mexicana. México: CIESAS-Conaculta-Ediciones de la Reina Roja.

Price, Barbara J. 1978. «Demystification, Enriddlement, and Aztec Cannibalism: A Materialist Rejoinder to Harner». American Ethnologist 5 (1): 98-115.

Ramos-Elorduy de Conconi, Julieta. 1987. Los insectos como fuente de proteinas en el futuro. México: Editorial Limusa.

Restall, Matthew. 2005. Los siete mitos de la conquista española. México: Paidós.

Reyes García, Luis, Eustaquio Celestino Solís, Armando Valencia Ríos, Constantino Medina Lima y Gregorio Guerrero Díaz. 1996. Documentos nahuas de la Ciudad de México del siglo XVI. México: CIESAS-Archivo General de la Nación.

Rivero Franyutti, Agustín. 2011. «Lo que la palabra natura revela acerca del discurso de Bernal Díaz del Castillo». Revista Internacional de Lingüistica Iberoamericana 18: 237 254.

Rojas, José Luis de. 2016. «Los indios novohispanos en la evangelización: ¿imposición o adaptaciones?». Revista Española de Antropología Americana 46: 141-154.

Ruvalcaba Mercado, Jesús. 1999. «Prehispanic Cannibalism, Human Sacrifices and Protein Intake among Several Mesoamerican Groups», en Il cibo culturale. Dal cibo alla cultu- 
ra, dalla cultura al cibo. Cultural Food. From Food to Culture, From Culture to Food, Antonio Guerci, ed., pp.183-193. Génova: Erga Edizione.

—. 2017. «Comidas y dietas en Europa y Mesoamérica durante el siglo XVI». Perspectivas Latinoamericanas 14: 1-22.

Sahagún, Fray Bernardino de. 2006. Historia general de las cosas de Nueva España. México: Porrúa.

Santley, Robert S. y Eric K. Rose. 1979. «Diet, Nutrition and Population Dynamics in the Basin of Mexico». World Archaeology 11 (2): 185-207.

Staller, John Edward. 2010. «Ethnohistoric Sources on Foodways, Feast, and Festivals in Mesoamerica», en Pre-Columbian Foodways. Interdisciplinary Approaches to Food, Culture, and Markets in Ancient Mesoamerica, John E. Staller y Michael Carrasco, eds., pp. 23-69. Nueva York: Springer.

Torquemada, Fray Juan de. 1975. Monarquía indiana, 3 vols. México: Editorial Porrúa. 